\title{
A rare cause of inguinal abscess: perforated appendicitis due to foreign body in Amyand's hernia
}

\author{
Tugay Tartar ${ }^{1 \oplus}$, Mehmet Saraç ${ }^{1 \oplus}$, Ünal Bakal $^{1 \oplus}$, Mehmet Ruhi Onur ${ }^{2 \oplus}$, \\ Ahmet Kazez ${ }^{1 \odot}$ \\ ${ }^{1}$ Department of Pediatric Surgery, Firat University Faculty of Medicine, Elazı̆̆; ${ }^{2}$ Department of Radiology, Hacettepe University \\ Faculty of Medicine, Ankara, Turkey.
}

\begin{abstract}
Background. Amyand's hernia is rarely noted in children, and appendicitis caused by a foreign body in Amyand's hernia is even rarer.

Case. A 2-year-old girl presented with recurrent conglomerate lymph node enlargements and an abscess in the right groin existing for one year despite medical treatment. Direct radiography revealed a foreign body in the right inguinal region. Computed tomography showed a foreign body and soft tissue inflammation in the inguinal canal. Laparotomy was performed, and Amyand's hernia was diagnosed. A foreign body was found in the lumen of the appendix vermiformis causing perforated appendicitis. This case is presented because of its rarity and unusual clinical presentation.
\end{abstract}

Conclusion. Amyand's hernia should be considered in paediatric cases with the history of recurrent inguinal abscesses.

Key words: Amyand's hernia, inguinal abscess, perforated appendicitis, foreign body.

Amyand's hernia (AH) was first described in 1735 by Claudius Amyand in an 11-yearold male patient. ${ }^{1}$ The incidence of acute appendicitis (AA) within an inguinal hernia is approximately $0.13 \% .^{2,3}$ Preoperative diagnosis is rather difficult despite advances in imaging modalities. ${ }^{3,4}$ This case is presented to emphasise this rare comorbidity and to highlight that $\mathrm{AH}$ should be considered in cases with a foreign body in the inguinal canal and inguinal abscess.

\section{Case Report}

A 2-year-old girl was admitted to a paediatric haematology clinic one year ago with complaints of swelling and redness in her right groin, and antibiotic treatment was

\footnotetext{
$凶$ Tugay Tartar

tugaytartar@gmail.com
}

Received 25th March 2020, revised 22nd April 2020,

11st May 2020, accepted 12th May 2020. administered. Clinical findings improved, and the patient was discharged. Two months previously, antibiotic treatment was started again due to the same complaints. Since needle biopsy results were compatible with abscess, the patient was referred to our clinic. The general condition of the patient was well, and her body temperature was $38.5^{\circ} \mathrm{C}$. Physical examination revealed swelling, redness and local temperature increase in the right inguinal region (Fig. 1). Blood biochemistry values were normal. White blood cell count was $16530 / \mathrm{mm}^{3}$, erythrocyte sedimentation rate was $60 \mathrm{~mm} / \mathrm{h}$, and C-reactive protein level was $71.5 \mathrm{mg} / \mathrm{L}$. Direct abdominal radiography revealed an opacity in the right inguinal region, which was attributed to a foreign body (Fig. 2). Inguinal ultrasonography (US) performed with linear probe revealed a fluid collection with highdensity content in the edematous subcutaneus fat tissue and accompanying multiple lymph nodes. Pelvic computed tomography (CT) revealed a $31 \times 35 \times 42 \mathrm{~mm}$ (anteriorposterior $x$ 


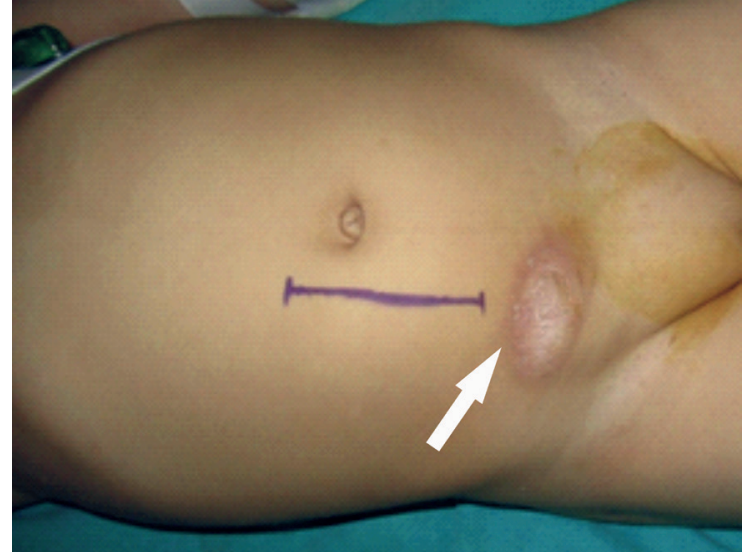

Fig. 1. Perioperative view (abscess and incision site in the right inguinal area).

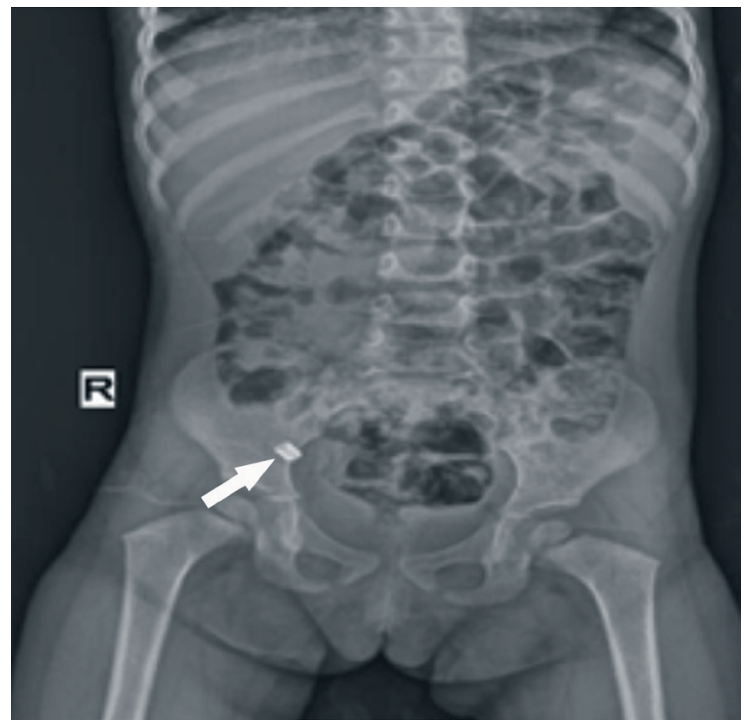

Fig. 2. Abdominal X-ray image demonstrates a radiopaque foreign body (arrow) in the right lower quadrant.

transverse $x$ longitudinal) mass with soft tissue density in the subcutaneous compartment of right lower quadrant. A $10-\mathrm{mm}$ foreign body with hyperdense appearance was located posterior to this lesion and close to the anterior abdominal wall in the abdomen. On laparotomy, the intra-abdominal area was clean. The appendix was found to be herniating in the hernial sac $(\mathrm{AH})$ through the opening in the right internal inguinal ring. The appendix was reduced and noted to be perforated, and an abscess in the inguinal canal was detected.
Appendectomy, abscess drainage and inguinal hernia repair were performed. The foreign body (metal lid??) found in the lower right quadrant on perioperative radiography was not detected on radiography following appendectomy. Examination of the removed appendix showed that the foreign body was located distal to the appendix (Fig. 3). The patient was discharged on $6^{\text {th }}$ postoperative day.

Informed consent was obtained from the patient's parents for publication.

\section{Discussion}

Faecal deposits, infections, tumours, and rarely foreign bodies $(0.005 \%)$ constitute underlying causes in the pathophysiology of appendicitis. ${ }^{5-7}$ $\mathrm{AH}$ is a rare pathology. ${ }^{2,3}$ It is defined as the inflamed or non-inflamed appendix entering the inguinal canal through the inguinal hernial sac. ${ }^{1,2}$ AH occurring with a foreign body is a much rarer condition. ${ }^{8} \mathrm{AH}$ is frequently detected in boys and on the right side due to the anatomical location of the ovarian tissue in girls. ${ }^{9}$ The vast majority of $\mathrm{AH}$ cases are diagnosed within the first 6 months of life $(85.7 \%){ }^{3}$

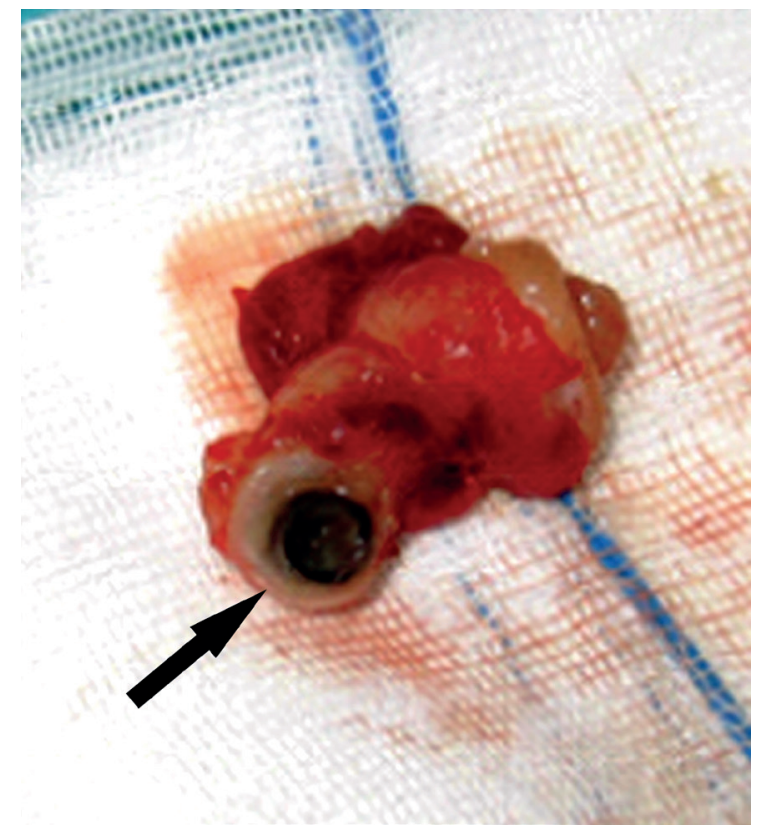

Fig. 3. Image of the foreign body (arrow) in the appendicular lumen. 
$\mathrm{AH}$ is usually identified during surgery.10 Ultrasonography and CT are used for the identification of $\mathrm{AH}$. However, imaging modalities are not routinely used for the diagnosis of inguinal hernias. ${ }^{4,11}$ Unlike those in the literature, the present study reported the case of a 2-year-old female. The appendix had entered the right inguinal canal, and perforated appendicitis and abscess had developed due to the foreign body in it. The clinical picture, which was treated at the haematology clinic one year ago, was probably due to the same cause. However, radiography was not performed at that time. Foreign body in the right inguinal region and associated abscess development was predicted before the surgery; however, $\mathrm{AH}$ was defined perioperatively.

Differential diagnosis of inguinal masses in children include hernia (inguinal or femoral), lymphadenopathy, hydrocele, cyst of the canal of Nuck, abscess, hematoma, and malignant soft tissue tumors such as sarcoma. ${ }^{12}$ The reasons for inguinal lymphadenopathy were local infections, bugbite, diaper dermatitis, syphilis, lymphogranuloma venereum, autoimmune diseases, storage disorders and malignancies. ${ }^{13}$ Abdominal X-ray examinations may be performed if hernia is suspected and visualization of herniated bowel aimed. Most frequently preferred imaging technique in evaluation of inguinal mass is US. With its real-time imaging ability US is a mainstay imaging technique in inguinal hernia since herniating bowel or intraabdominal fat content may be visualized during valsalva maneuvre. US may be also used as a first-line imaging technique in the diagnosis of other inguinal mass-forming lesions such as enlarged lymph nodes, hydrocele, abscess and hematoma. CT or MRI may be required to interrogate the origin of the inguinal abscesses. Soft tissue sarcomas involving inguinal region should be evaluated with $\mathrm{CT}$ to determine the extent of these masses in the abdomen. ${ }^{14}$

The prevailing opinion in the treatment of $\mathrm{AH}$ is that appendectomy should not be performed in cases in which AA findings are absent, and the appendix can be reduced into the abdomen. ${ }^{2}$ Amyand hernia is frequently detected incidentally during inguinal hernia operations. For this reason, inguinal approach is performed in $\mathrm{AH}$ cases. Appendectomy through the sac and high ligation procedures can be performed through inguinal transverse incision performed during inguinal hernia treatment. In the present case, laparotomy was planned due to the presence of a foreign body in the inguinal region extending into the abdomen. Appendectomy, abscess drainage and debridement and intra-abdominal inguinal hernia repair were performed.

In conclusion, $\mathrm{AH}$ should be considered in cases with recurrent inguinal abscess regardless of the gender of the child.

\section{REFERENCES}

1. Hutchinson R. Amyand's hernia. J R Soc Med 1993; 86: 104-105

2. Sharma H, Gupta A, Shekhawat NS, Memon B, Memon MA. Amyand's hernia: a report of 18 consecutive patients over a 15 -year period. Hernia 2007; 11: 31-35.

3. Cigsar EB, Karadağ CA, Dokucu AI. Amyand's hernia: 11 years of experience. J Pediatr Surg 2016; 51: 1327-1329.

4. Akfirat M, Kazez A, Serhatlioğlu S. Preoperative sonografic diagnosis of sliding appendiceal inguinal hernia. J Clin Ultrasound 1999; 27: 156-158.

5. Miller GG, Fraser GC, Jevon G. 'Pilonidal appendicitis' or 'the hair of the dog': an unusual case of foreign body perforation of the appendix. J Pediatr Surg 1996; 31: 703.

6. Klingler PJ, Seelig MH, DeVault KR, et al. Ingested foreign bodies within the appendix: a 100-year review of the literature. Dig Dis 1998; 16: 308-314.

7. Köseoğulları AA, Özel ŞK, Bakal Ü, Kazez A. Apandisitin nadir bir nedeni: meyve çekirdeği. Fırat Tip Dergisi 2006; 11: 73-74.

8. Llullaku SS, Hyseni NS, Kelmendi BZ, Jashari HJ, Hasani AS. A pin in appendix within Amyand's hernia in a six-years-old boy: case report and review of literature. World J Emerg Surg 2010; 5: 14.

9. Gupta S, Sharma R, Kaushik R. Left-sided Amyand's hernia. Singapore Med J 2005; 46: 424-425. 
10. Sarsu SB. Is appendectomy necessary in children with Amyand hernia? J Pediat Res 2016; 3: 50-52.

11. Maekawa T. Amyand's hernia diagnosed by computed tomography. Intern Med 2017; 56: 26792680 .

12. Sameshima YT, Yamanari MGI, Silva MA, Neto MJF, Funari MBG. The challenging sonographic inguinal canal evaluation in neonates and children: an update of differential diagnose. Pediatr Radiol 2017; 47: 461472 .
13. Ayata A. Çocukluk çağında lenfadenopatiler. Süleyman Demirel Üniversitesi Tıp Fakültesi Dergisi 2004; 11: 26-29.

14. Bhosale PR, Patnana M, Viswanathan C, Szklaruk J. The inguinal canal: anatomy and imaging features of common and uncommon masses. Radiographics 2008; 28: 819-835. 